\title{
Surface heterogeneity effects of activated carbons on the kinetics of paracetamol removal from aqueous solution
}

\author{
Ana S. Mestre ${ }^{\mathrm{a}}$, João Pires ${ }^{\mathrm{a}}$, José M.F. Nogueira ${ }^{\mathrm{a}}$, Jose B. Parra ${ }^{\mathrm{b}}$, Ana P. Carvalho ${ }^{\mathrm{a} * *}$, \\ Conchi O. Ania ${ }^{\mathrm{b}, *}$ \\ ${ }^{a}$ Departamento de Química e Bioquímica and CQB, Faculdade de Ciências da Universidade de Lisboa, Ed. \\ C8, Campo Grande, 1749-016 Lisboa (Portugal) \\ ${ }^{b}$ Energy and Environment Department, Instituto Nacional del Carbón, CSIC, Apdo. 73, 33011 Oviedo \\ (Spain)
}

*Corresponding Author: Ana P. Carvalho; Faculdade de Ciências da Universidade de Lisboa, Tel.: +351 217500897; Fax: +351 217500088; E-mail address: ana.carvalho@ff.ul.pt (Ana P. Carvalho); Conchi O. Ania; INCAR, CSIC, Tel.: +34985119090 Fax: +34 985297662; E-mail address: conchi@incar.csic.es (Conchi O. Ania)

\begin{abstract}
The removal of a widespread used drug (i.e., ibuprofen) from water was investigated using high valuable carbon adsorbents obtained from chemical and physical activation of a bioresource (cork) and a municipal waste (plastic). The waste-derived carbons outperformed the adsorption capacity of commercial carbonaceous adsorbents due to their adequate features for the removal of the targeted compound. Regarding the adsorption mechanism the results obtained point out that ibuprofen retention is favored in activated carbons with basic surface properties. On the other hand, the textural features also play an important role; the presence of a transport pores network (i.e., mesopores) is crucial to ensure the accessibility to the inner porosity and the microporosity must be large enough to accommodate the ibuprofen molecule. Specifically, adsorbents with a large fraction of ultramicropores (pore widths $<0.7 \mathrm{~nm}$ ) are not adequate to effectively remove ibuprofen.
\end{abstract}

\section{Keywords}




\section{Introduction}

During the last decades the scientific community is becoming increasingly concerned about the potential public health impact of new environmental contaminants originated from industrial, agricultural, and human activities. These compounds, known as emergent pollutants, include prescription and non-prescription human and veterinary pharmaceutical compounds and personal care products (PPCPs). However, little is known about the occurrence, fate, synergistic, and long-term effects of these pollutants and their metabolites following their end-use (Kolpin et al., 2002; Jones et al., 2005). Their control results very difficult due to the diversity of pollution sources; besides, once they have entered in the water stream, the contamination of rivers, lakes, aquifers and groundwater is a considerably high risk (Kolpin et al., 2002; Jones et al., 2005; Gomez et al., 2007).

Recent studies in Europe and North America have reported the occurrence of PPCPs in wastewater and ambient waters (Daughton and Ternes, 1999; Kolpin et al., 2002). In the case of pharmaceuticals, it was demonstrated that conventional wastewater treatments are not effective to eliminate and/or degrade the majority of these compounds. They are partially eliminated; therefore residual quantities remain in treated water, and have been found to accumulate in drinking (tap) water (Ahmad et al., 1999; Hernando et al., 2006).

Being water an essential resource for life in all ecosystems, a great effort have been made in the past decades to modify the water sector technologies in order to improve the water quality. In this sense adsorption has became a well-established technique to remove pollutants, being activated carbon the prevailing adsorbent for the purification of water with low pollutant concentration. The major drawbacks are a poor economic feasibility, limited applicability and effectiveness, and a short lifetime, often due to low and expensive regeneration capacities. Generally, the loaded carbon is regenerated ex-situ by heating or steaming, which are a high energy-consuming process and, although the efficiency is relatively high, there is a considerable loss of activated carbon (Roskill Report, 1998).

An alternative is to use a low-cost adsorbent that does not represent an economic cornerstone for the large scale implementation of advanced water treatments based on adsorption processes. On the other hand, the 
performance of the adsorbent also plays an outstanding role on the economic feasibility of the overall adsorption process and should not be disregarded. In this sense, the utilization of residues as precursors of low-cost high-value carbon adsorbents is an interesting strategy that enables to deal with the problem of waste disposal and recycling (Karagöz et al., 2008; Michailof et al., 2008; Wang et al., 2008). In this work two widely produced residues were used for the preparation of low-cost high-value carbon materials: cork powder, an agro-industrial residue from cork processing and a municipal waste, poly(ethylene terephthalate) - PET -from used plastic bottles.

Portugal produces yearly around 185000 ton of cork, which represents more than $50 \%$ of the world production (Sousa et al., 2006). The most important by-product of cork processing is cork powder since, in average, $25-30 \%$ of the cork processed is transformed in cork powder (Silva et al., 2005) and calculations based on the forest production, industrial yields and quantities of different cork products indicates that, in Portugal 32 000-37 000 ton of cork powder are produced annually (Gil, 1997). This residue is usually used as fuel at the cork processing plants ending up as a low-value heat with no practical use. On the other hand, the residue from PET bottles has became one of the major post-consumer plastic waste (Parra et al., 2004, 2006), since the world's annual consumption of plastic materials has increased sharply from around 5 million tones in the 1950 s to nearly 100 million tones today. Particularly, PET consumption has recorded the fastest growth rate in the global plastic market due to ongoing expansion of the PET bottle market (Association of plastic manufacturers in Europe). The current PET consumption rate constitutes a relevant environmentally unsustainable problem, due to the huge amount of solid waste produced and to its low bio- and photodegradability. Pyrolysis could provide an alternative and economically viable route for processing PET waste; due to the potential uses of different by-products in several fields of application: energy from the pyrolysis gases, recovery of terephthalic acid and other subproducts, and a solid carbonaceous residue which has shown a high textural development after activation.

Details on the preparation of the adsorbents from both residues, as well as some characterization parameters of the materials obtained have been reported in previous studies (Parra et al., 2004; Mestre et al., 2007), therefore in this paper we focus on the adsorption capability of the prepared adsorbents, linked to their textural and chemical features. As probe molecule, we have selected ibuprofen, one of the most worldwide 
consumed pharmaceuticals. It is a nonsteroidal anti-inflammatory analgesic and antipyretic compound, which has become very popular for the treatment of rheumatic disorders, pain and fever. Being slightly soluble in water, it is readily soluble in organic solvents, and so it has high mobility in the aquatic environment. Moreover, recent studies have shown that it is frequently found in all sorts of waters in many European countries (POSEIDON, 2004).

\section{Methods}

\subsection{Adsorbents}

Several activated carbons have been prepared from cork powder and PET residues for the adsorption of ibuprofen from aqueous phase. CAC and CPAC samples were prepared using cork powder waste (fraction $<0.297 \mathrm{~mm}$ ) as raw material, following the experimental procedure described in (Mestre et al., 2007). Briefly, one sample was obtained by Chemical Activation of Cork (carbon $\mathrm{CAC}$ ) with $\mathrm{K}_{2} \mathrm{CO}_{3}$ at $700{ }^{\circ} \mathrm{C}$ for 1h (burn off degree $88 \%$ ); a second sample was prepared by further physical activation of sample CAC with steam at $750{ }^{\circ} \mathrm{C}$ for $1 \mathrm{~h}$ up to a burn-off degree in the physical activation of $66 \%$ (sample CPAC). The carbon $\mathrm{P}$ was obtained from physical activation of PET waste at $925^{\circ} \mathrm{C}$ under $\mathrm{CO}_{2}$ atmosphere up to a burn-off degree

$38 \%$. Further details about the experimental procedure and the optimization of the synthesis parameters of the PET-derived carbon sample have been previously reported (Parra et al., 2004).

Two commercial activated carbons commonly used in water treatment and obtained from physical activation of coal -Q- and wood -LS- were selected for comparison purposes. Additionally, to explore the role of the surface chemistry on the adsorption process, the activated carbon LSN was obtained by wet oxidation in boiling $20 \%$ nitric acid of LS carbon (1gram carbon/10 $\mathrm{cm}^{3} \mathrm{HNO}_{3}$ solution) until dryness, as described elsewhere (Ania et al., 2004). Before usage, all the samples were washed in distilled water at $60{ }^{\circ} \mathrm{C}$, dried at $110^{\circ} \mathrm{C}$ overnight and kept in a desiccator.

\subsection{Nanotextural and chemical characterization of the carbon samples}


Nanotexture of the carbon materials was characterized by $\mathrm{N}_{2}$ and $\mathrm{CO}_{2}$ adsorption at -196 and $0{ }^{\circ} \mathrm{C}$, respectively, in conventional volumetric apparatus (ASAP 2000 and Tristar 3000, from Micromeritics). Before the experiments, the samples were outgassed under vacuum at $300{ }^{\circ} \mathrm{C}$ for overnight. The isotherms were used to calculate the specific surface area, $S_{\mathrm{BET}}$, total pore volume, $V_{\mathrm{TOTAL}}$, and pore size distribution. The pore size distributions (PSD) were evaluated using the density functional theory (DFT). Additionally, the distribution of pores smaller than $0.7 \mathrm{~nm}$ (ultra-micropores) was assessed from $\mathrm{CO}_{2}$ adsorption isotherms at $0{ }^{\circ} \mathrm{C}$ with DR formulism. The samples were further characterized by the determination of the $\mathrm{pH}$ at the point of zero charge $\left(\mathrm{pH}_{\mathrm{PZC}}\right)$ and the oxygen content (directly measured in a LECO VTF-900 analyzer). The $\mathrm{pH}_{\mathrm{PZC}}$ was estimated using the mass titration procedure (Noh and Schwarz, 1989). Briefly, $0.25 \mathrm{~g}$ of granular activated carbon was dispersed in a suitable volume of distilled water and stored with constant stirring under a nitrogen atmosphere at room temperature until equilibrium was attained (ca. 48 h). Typical activated carbon/water ratios (in \%) employed were 1, 2, 4, 6, 8, 10, 12, 14 and 16. Once equilibrium had been reached, the $\mathrm{pH}$ value was measured via a glass electrode. Newly distilled water was then added in order to obtain the next solid/weight fraction. The plateau in the plot of equilibrium $\mathrm{pH}$ versus solid weight fraction corresponded to the $\mathrm{pH}_{\mathrm{PZC}}$ value of the activated carbon.

\subsection{Ibuprofen adsorption: kinetics and equilibrium assays}

Ibuprofen is the common name of 2-[4-(2-methylpropyl)phenyl]propanoic acid $\left(\mathrm{C}_{13} \mathrm{H}_{18} \mathrm{O}_{2}\right.$, CAS number 15687-27-1). It was synthesized by Shasun Chemicals and Drugs Ltd. (lot IBU0307598). All the used ibuprofen solutions contained $10 \%$ of methanol (Methanol Chromasolv for HPLC, $99.9 \%$, Sigma Aldrich) and were prepared with ultra-pure water obtained from Milli-Q water purification systems. The solutions used in kinetic and equilibrium assays were prepared without $\mathrm{pH}$ adjustment, presenting values around 4.

To study the adsorption kinetics, $15 \mathrm{~cm}^{3}$ of ibuprofen solution (initial concentration $90 \mathrm{mg} \mathrm{dm}^{-3}$ ) were mixed with ca. $10 \mathrm{mg}$ of activated carbon in glass vials (Macherey-Nagel, Düren). After introducing a magnetic stir bar, the vials were sealed using a hand crimper. The sealed vials were placed in a water bath at $30{ }^{\circ} \mathrm{C}$ (controlled with a Eurotherm 2216L device) and stirred at $700 \mathrm{rpm}$ in a multipoint agitation plate (Variomag Multipoint). The time recording was started when the stirring began and several samples were collected 
between $5 \mathrm{~min}$ and $6 \mathrm{~h}$. After filtration, the amount of ibuprofen was determined. Ibuprofen uptake was calculated according to Eq. (1)

$q_{t}=\frac{\left(C_{0}-C_{t}\right)}{W} V$

where $q_{\mathrm{t}}$ is the amount $\left(\mathrm{mg} \mathrm{g}^{-1}\right)$ of ibuprofen adsorbed at time $t, C_{0}$ is the ibuprofen initial concentration (mg $\left.\mathrm{dm}^{-3}\right), C_{\mathrm{t}}$ is the ibuprofen concentration at time $t\left(\mathrm{mg} \mathrm{dm}^{-3}\right), V$ is the volume $\left(\mathrm{dm}^{3}\right)$ of the adsorbate solution and $W$ is the weight $(\mathrm{g})$ of dried carbon.

Equilibrium adsorption studies were carried out at $30^{\circ} \mathrm{C}$ varying the adsorbent doses $(2.5-10 \mathrm{mg})$, the solution volumes $\left(15\right.$ and $\left.30 \mathrm{~cm}^{3}\right)$ and the ibuprofen concentrations $\left(20-120 \mathrm{mg} \mathrm{dm}^{-3}\right)$. After stirring for $4 \mathrm{~h}$ the concentration of ibuprofen remaining in solution at equilibrium $\left(C_{e}\right)$ was determined and the uptake $\left(q_{\mathrm{e}}\right)$ was calculated using Eq. (1). The stirring time of $4 \mathrm{~h}$ was selected for the equilibrium assays since, according with the results of the kinetic assays; between 2 and $6 \mathrm{~h}$ the ibuprofen uptake was practically the same and did not change even after $24 \mathrm{~h}$ of stirring. All adsorption assays were made in triplicate. The influence of initial $\mathrm{pH}$ was studied over a $\mathrm{pH}$ range between 2 and 11 , for $15 \mathrm{~cm}^{3}$ of solution with concentration of $60 \mathrm{mg} \mathrm{dm}^{-3}$ using $10 \mathrm{mg}$ of activated carbon. For this, hydrochloric acid or sodium hydroxide was added to the ibuprofen solution to adjust the desired $\mathrm{pH}$.

The initial and residual concentrations of ibuprofen were analyzed by high performance liquid chromatography in an Agilent 1100 series LC chromatographic apparatus equipped with a UV detector. Details on the experimental procedure have been described elsewhere (Mestre et al., 2007). Briefly a Tracer excel 120 OctaDecilSilica-A column was used; the mobile phase consisted on a mixture of $75 \%(\mathrm{v} / \mathrm{v})$ methanol solution (solvent A) and ultra-pure water with $0.1 \% \mathrm{H}_{3} \mathrm{PO}_{4}$ (solvent B), with flow of $1 \mathrm{~cm}^{3} \mathrm{~min}^{-1}$. The detector was set at $220 \mathrm{~nm}$, the column temperature was maintained at $25^{\circ} \mathrm{C}$ and the injection volume

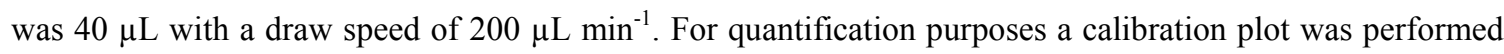
under the instrumental conditions used.

\section{Results and Discussion}




\subsection{Characterization of the adsorbents}

In this study, two residues (cork powder and plastic wastes) have been used as carbon precursors for the preparation of low-cost highly porous adsorbents. Details on the optimization of the synthesis conditions have been discussed in previous investigations (Carvalho et al., 2004, 2006; Mestre et al., 2007; Parra et al., 2004, 2006) and remain out of the scope of this paper, which is devoted to the potential application of these wastederived adsorbents for the removal of pharmaceuticals from aqueous phase. Nevertheless for data interpretation purposes, the main textural parameters of the synthesized carbons are reported in Table 1.

The $\mathrm{N}_{2}$ adsorption isotherms (not shown) of the carbons obtained from activation of cork and PET residues (samples CAC and P, respectively) belong to type I in the BDDT classification (Brunauer et al., 1940), with a sharp knee at low relative pressures, indicating that the microporosity of these samples is mainly composed of pores of small diameter. A further analysis of the PSD combining the information of $\mathrm{N}_{2}$ and $\mathrm{CO}_{2}$ adsorption isotherms indicated that the pore volume determined by $\mathrm{CO}_{2}$ data in $\mathrm{CAC}$ carbon is larger than the corresponding volume of micropores "seen" by $\mathrm{N}_{2}$, confirming that the narrow microporosity (ultramicropores, pore widths $<0.7 \mathrm{~nm}$ ) represents an important contribution for the overall porosity of this carbon. Moreover, the volume of mesopores accounts for less than $10 \%$ of the overall porosity in CAC and P carbons, confirming their mainly microporous nature.

The commercial activated carbons as well as CPAC, the carbon obtained by physical activation of CAC sample exhibit a type I with somewhat type IV character isotherms, pointing to microporous carbons with a considerable development of mesoporosity. These samples clearly present an opening of the knee of the $\mathrm{N}_{2}$ isotherms at low relative pressures, suggesting a widening of the microporosity. This is in good agreement with the data obtained from $\mathrm{CO}_{2}$ adsorption isotherms and with the average micropore width -L- evaluated from the Stoeckli-Ballerini equation (see Table 1) (Stoeckli and Ballerini, 1991). The $\mathrm{N}_{2}$ adsorption isotherms also show a H4-type hysteresis loop, characteristic of the slit-shaped pores where the adsorption and desorption branches are parallel.

The oxidized sample -LSN- showed only a slight decrease in the nitrogen uptake, as compared to the initial counterpart -LS sample-, indicating a minor modification in the pore volume and pore sizes. It can be then 
concluded that both samples present similar textural properties and different surface chemistry (as inferred from the elemental analysis) due to the incorporation of oxygen containing surface groups in the carbon upon oxidation.

As regards the surface chemistry the values of the $\mathrm{pH}_{\mathrm{PZC}}$ revealed that the studied activated carbons possess predominantly basic nature (except for LSN), despite their different oxygen contents. It is worth noting that whereas the carbon prepared from plastic waste -P- presents negligible oxygen content, the cork-derived carbons -CAC and CPAC- exhibit large amounts of oxygen. Such combination of chemical features (i.e., high oxygen content and basic character) being rather unusual in activated carbons, is attributed to the chemical composition of the raw precursor. Cork powder is an enriched source of suberin, which chemical composition and microstructure is very different from that in wood or other lignocellulosic materials. The typical composition of cork is $45 \%$ suberin, $27 \%$ lignin, $12 \%$ polysaccharides (cellulose and hemicellulose), $6 \%$ waxes and $6 \%$ tannins (Carrott et al., 1999), being suberin a polymeric material with ester and phenolic functionalities. It is plausible that after activation of the cork powder, the ester and phenol-like functionalities are incorporated to the basal planes of the carbon, likely as ether, furanic and/or chromene-like structures. As a result, the activated carbon exhibits high oxygen content; however these functionalities remaining inside the carbonaceous matrix, as opposed to the majority of activated carbons where they are typically located at the edges of the basal planes in the graphene layers. Earlier studies in our research group (Cardoso et al., 2008) and those of Carrott and co-workers (Carrott et al., 1999) also report unusual properties in the activated carbons obtained from cork activation, when compared to those from common precursors.

Concerning LSN carbon, as expected the oxidation brought about the incorporation of oxygen containing surface groups mainly from acidic nature, as confirmed by the decrease in the $\mathrm{pH}_{\mathrm{PZC}}$ value (ca. 4 units).

\subsection{Ibuprofen adsorption}

\subsubsection{Kinetic studies}

Adsorption kinetics must be investigated in order to determine the time necessary for reaching equilibrium, and to elucidate the mechanism of the adsorption process. The rate of ibuprofen adsorption on the selected 
carbons was studied by measuring the concentration change as a function of time, keeping constant the volume, the initial concentration and the mass of adsorbent. The results are displayed in Figure 1. In all cases, the experimental data were fitted by a pseudo-second-order kinetics (Ho, 2006), with correlation coefficients higher than 0.99 (Table 2). The experimental data were also fitted to the pseudo-first order kinetic model, but the correlations obtained (not shown) were very unfavorable.

Concerning the pseudo-second order rate constant, $k_{2}$, the values quoted in Table 2 decrease in the order: $\mathrm{LS}>\mathrm{LSN} \sim \mathrm{CPAC}>\mathrm{Q}>\mathrm{CAC} \sim \mathrm{P}$. Larger values are obtained for the commercial activated carbons, when compared to the waste-derived adsorbents, except for CPAC carbon. This behavior should be linked to the presence, or not, of transport pores (mesopores) in the structure of the carbons (Table 1). Actually, the two carbons that presented the slowest adsorption kinetics -P and CAC-, possess negligible $V_{\text {meso. }}$ On the other hand, the fastest adsorption rate took place in the carbon with the most developed mesopore network, LS. In fact, excluding CAC and $\mathrm{P}$ samples (due to their almost absence of $V_{\text {meso }}$ ), an almost linear tendency is obtained between $V_{\text {meso }}$ and the $k_{2} \operatorname{costant}\left(R^{2}=0.97\right)$. The same trends were obtained for $h$ (initial adsorption rate) and $t_{1 / 2}$ (half-life time) parameters confirming the faster adsorption rate in the carbons with high $V_{\text {meso }}$. For instance, $t_{1 / 2}$ of CAC and P samples are, respectively, 10 and 8 times, the value presented by the carbon LS.

Given the dimensions computed for ibuprofen $(1.03 \times 0.52 \times 0.43$; computed dimensions for the lowest energy configuration, Mestre et al., 2007), this finding is in good agreement with what is known about the importance of the presence of transport pores in the rate of adsorption of molecules of rather large dimensions such as ibuprofen.

\subsubsection{Effect of solution $\mathrm{pH}$}

It is well known that solution $\mathrm{pH}$ is a critical factor in adsorption from solution, particularly in the case of weak electrolytes which ionization form strongly depends on the solution $\mathrm{pH}$. Being ibuprofen a weak electrolyte ( $\mathrm{pK}_{\mathrm{a}}$ 4.91; Lindqvist et al., 2005) we have studied the removal efficiency at different solution $\mathrm{pH}$ (Figure 2) for all the selected adsorbents. 
It can be observed that loading capacities decreased at basic solution $\mathrm{pH}$ for all the carbons, although the extent of this decrease is strongly dependent on the nature of the adsorbent. For instance, $\mathrm{P}$ and CPAC carbons showed a smaller dependence of the removal efficiency with the $\mathrm{pH}$ values, when compared to the rest of the counterparts. On the other hand, ibuprofen removal efficiency decreased dramatically for CAC and LSN carbons, especially at basic solution $\mathrm{pH}$ (ca. $60 \%$ at $\mathrm{pH}$ 9). This behavior is linked with two factors: the ionization of the adsorbate and the charges on the carbon surface at a given $\mathrm{pH}$.

On the first hand, $\mathrm{pH}$ changes affect the dissociation of the ibuprofen molecule. According to the dissociation constant ( $\mathrm{pK}_{\mathrm{a}}$ 4.91; Lindqvist et al., 2005), the neutral molecule is the main structure in solution at $\mathrm{pH} 2$, accounting for more than $99 \mathrm{~mol} \%$. By contrast, the conversion of ibuprofen into its anionic form starts to be important in the $\mathrm{pH}$ range above 4 . At $\mathrm{pH} 4$ the anionic form accounts for $11 \mathrm{~mol} \%$, at $\mathrm{pH} 5$ accounts for 55 mol \% and at $\mathrm{pH} 7$ it represents more than $99 \mathrm{~mol} \%$. Therefore, the decrease in the amount adsorbed at basic solution $\mathrm{pH}$ suggests a weaker interaction of the carbon surface with deprotonated ibuprofen (dominant in solution).

On the other hand, $\mathrm{pH}$ changes also affect the surface chemistry of the adsorbent due to the dissociation of the functional groups. The carbon surface may be either positively or negatively charged depending on the nature of the activated carbon; therefore, at a given $\mathrm{pH}$, the carbon surface and the adsorbate species may coexist in a complex system, in which the same or opposite charges may be present. When adsorption occurs above $\mathrm{pH} 5$, the anionic form of ibuprofen is dominant in solution $\left(\mathrm{pH}>\mathrm{pK}_{\mathrm{a}}\right)$ and additionally negatively charged surface sites exist on the activated carbons when the $\mathrm{pH}_{\mathrm{PZC}}<$ solution $\mathrm{pH}$. In this case, the adsorption capacity is drastically reduced since negative charges along the edges of the graphitic layers repel the ibuprofen anions (see results of LSN at $\mathrm{pH}$ 9). At acidic $\mathrm{pH}$ in contrast, the negative charges at the edge of graphene layers are neutralized (all acidic groups are protonated, and carbons are either neutral of positively charged), whereas ibuprofen is mainly non-dissociated; thus repulsive electrostatic interactions are minimized and adsorption is enhanced. This also suggests that ibuprofen is preferentially adsorbed in a neutral form and in activated carbons of basic character. Based on the obtained results, the $\mathrm{pH}_{\mathrm{PZC}}$ value seems to be an excellent marker of ibuprofen removal on activated carbons from aqueous solution, as it can be inferred from Figure 2 . 
Another interesting point is that the residue-derived carbons -CPAC and P- are more adequate for the uptake of ibuprofen than the commercial ones, since they present high ibuprofen uptakes over a long $\mathrm{pH}$ range. This is most likely linked to the nature of the carbon precursor, which yielded carbons with adequate basicity.

In the case of the carbon obtained from plastic waste, the corresponding char and activated material have extremely low oxygen content (Table 1 and Parra et al., 2004), and the basicity is associated to the delocalized $\pi$ electron density of the graphene layers, capable of acting as Lewis base sites adsorbing protons (Montes-Moran et al., 1998). In the case of cork powder, the contribution of oxygen-containing surface groups of basic nature, including pyrone and/or chromene-like type cannot be disregarded. This is in good agreement with the results of Boehm titration for CPAC carbon, previously reported (Mestre et al., 2007). From the amount of total acidic groups determined by Boehm titration (110 meq/100 $\mathrm{g}$ of adsorbent), and the total oxygen content, the value of total basic groups can be estimated in ca. $80 \%$ of the overall oxygen content. The issue of the basicity of the cork-derived carbons remains currently under investigation.

Additional support for the role of basic groups can be obtained analyzing the behavior of LS and LSN carbons. Given that those carbons have similar porous features; the fall in the uptake of ibuprofen upon oxidation -LSN- can only be attributed to the modification of the surface chemistry. The decrease in the amount adsorbed after oxidation is most probably due to the alteration of the $\pi$ electronic density on the carbon surface as a result of the functionalization. Given the partially aromatic structure of ibuprofen, dispersion forces should be expected between the $\pi$ electron density of the basal planes of the carbons and the aromatic ring of the adsorbate. It is well known that functionalization of the carbon withdraws $\pi$-electrons from the graphene layers (Donnet, 1982), therefore the contribution of dispersive interactions to adsorption is lessened. Competitive adsorption of water molecules should also be considered, as the carbon becomes more hydrophilic upon oxidation. The oxygen groups promote the formation of hydration clusters at the entrance of the pores that effectively reduce and/or hinder the accessibility and affinity of ibuprofen to the inner porous texture of the carbon (Franz et al., 2000). This also explains the slower adsorption rate of LSN vs LS sample. 


\subsubsection{Equilibrium adsorption isotherms}

Figure 3 illustrates the ibuprofen adsorption isotherms on the studied carbons. Most of them (i.e., CAC, CPAC, P and Q samples) belong to the L type in the Giles classification (Giles et al., 1960), showing a steep initial rise and a concave curvature at low equilibrium concentrations followed by a plateau or saturation limit. This is characteristic of systems where the adsorbate presents high affinity towards the adsorbent, and therefore indicates that no strong competition of the solvent takes place for the active sites of adsorption. In the case of LS and LSN carbons the adsorption isotherms present a less concave curvature; the amount adsorbed steadily increases and the saturation limit at low adsorbent doses is not attained. The differences in the shape of the isotherms are crucial for the choice of a theoretical model that fits the experimental data and enables to calculate the adsorption capacity of the materials.

It is remarkable that LS and LSN isotherms are parallel over the whole range of concentrations, being the amount adsorbed about 2 times lower for LSN carbon. As stated before, the oxidation of the carbon did not practically alter the porous features of the adsorbent, for which this behavior is only attributed to differences in surface chemistry.

As above-mentioned, oxidation of LS carbon resulted in an increase by 4 times in the oxygen content; at the same time, most of the created groups are of acidic nature (see $\mathrm{pH}_{\mathrm{PZC}}$ ). Being ibuprofen a weak acidic probe $\left(\mathrm{pK}_{\mathrm{a}} \sim 4.91\right)$, modifications on the chemistry of the adsorbent drastically affects the nature of the adsorption forces. Adsorption isotherms were carried out at $\mathrm{pH} \mathrm{4,} \mathrm{at} \mathrm{which} \mathrm{ibuprofen} \mathrm{is} \mathrm{mainly} \mathrm{under} \mathrm{neutral} \mathrm{form}$ (90:10 mol \% neutral to anionic form). At this solution $\mathrm{pH}$, sample LS is mainly positively charged $\left(\mathrm{pH}_{\mathrm{PZC}}\right.$ 8.2). In contrast, $\mathrm{LSN}$ is either neutral or slightly positive as solution $\mathrm{pH}$ is close to its $\mathrm{pH}_{\mathrm{PZC}}$ (4.5). Consequently, the fall in the amount adsorbed in LSN carbon is likely attributed to the water competition. Hence, the surface should be more densely populated by water molecules that aggregate in hydration clusters avoiding ibuprofen molecules to reach the active sites of adsorption (i.e., micropores and regions of high $\pi$ electron density). So, the functionalization of the carbon causes a decrease in ibuprofen affinity (i.e., hydrophilic character and weaker adsorption forces). This is in good agreement with the results inferred from kinetic data, confirming the outstanding role of the adsorbent's surface chemistry and the effect of solution $\mathrm{pH}$ on the retention of ibuprofen. 
To obtain the maximum adsorption capacity at equilibrium, experimental isotherms were fitted to classical Freundlich and Langmuir models. The results are compiled in Table 3, along with the fitting parameters and results of the non-linear chi-square test analysis, $\chi^{2}$ (Ho, 2004). If the values calculated from the model are similar to experimental data, $\chi^{2}$ should be a small number and vice-versa. The adsorption isotherms showed a rather good agreement with Langmuir model, except for LS and LSN carbons that presented a better fitting to the Freundlich model. This behavior is explained in terms of the different assumptions of both theoretical models.

Langmuir theory (Langmuir, 1918) is based on the assumption that the surface of the adsorbent is energetically homogenous and that a monolayer surface coverage is formed with no interactions between molecules adsorbed. On the other hand, the Freundlich model (Freundlich, 1926) is an empirical equation that was originally developed to overcome some limitations of the Langmuir theory, by taking into account the surface heterogeneity and that there might exist intermolecular interactions between the adsorbate molecules. Hence, the Langmuir model cannot adequately fit those isotherms where the saturation limit is not reached, which happens to be the case of LS and LSN carbons, as above-mentioned when describing the shape of the isotherms. This behavior is also indicative of a low affinity of ibuprofen by these two adsorbents. Nevertheless, for comparison purposes we have use the adsorption capacities obtained from Langmuir equation, having in mind that the interpretation of LS and LSN samples must be done with care.

The adsorption capacities, $q_{\mathrm{m}}$, increase according to the following order: $\mathrm{CAC} \sim \mathrm{LSN}<\mathrm{P}<\mathrm{LS}<\mathrm{CPAC}<\mathrm{Q}$. This trend has to be linked to both porous and chemical features of the adsorbents. However, it appears that the uptake is not related to the apparent surface area since, for instance, the carbon with the largest $S_{\mathrm{BET}}$ value -Phas not the higher ibuprofen uptake. On the other hand, the trend does not follow the expected tendency according to the $\mathrm{pH}_{\mathrm{PZC}}$ of the carbons, since as previously discussed, ibuprofen adsorption is favored in basic carbons, but not all basic carbons present the large ibuprofen adsorption capacity that should be, a priori, expected, as is the case of sample $\mathrm{P}$.

Typically micropores (and particularly narrow micropores) are considered active sites of adsorption from both gas and liquid phase where the adsorption potential is higher (Ania and Bandosz, 2005); nevertheless, we have found that the carbon with the lowest narrow micropore volume, Q, outperforms ibuprofen retention 
on the rest of the adsorbents. In fact, a closer look to the isotherms showed no correlation between the loading capacities and the narrow microporosity of the carbons evaluated from $\mathrm{CO}_{2}$ adsorption data (Table 1 and Figure 4).

This finding suggests that the dimensions of ibuprofen and perhaps its shape hinder its accessibility to the smallest pores of the activated carbons (despite two molecular dimensions of ibuprofen are below the sizes of the ultramicropores width, i.e. below $0.7 \mathrm{~nm}$ ). This suggests that size exclusion effects are occurring and points out that to understand the adsorption process one should take into account i) the volume of the narrow micropores, ii) their dimensions and also iii) their shape. Applying the DRS equation at the $\mathrm{CO}_{2}$ adsorption data (Dubinin and Stoeckli, 1980), the micropore size distribution of the carbons has been obtained (Figure 4). It can be easily seen that CAC does not only exhibit a large fraction of narrow micropores, but also displays a sharp narrow distribution of small pores centered at about $0.7 \mathrm{~nm}$. This finding would explain the low ibuprofen uptake of this carbon, where, despite its basic nature, micropores are too small to accommodate the ibuprofen probes.

LS and LSN carbons also exhibit rather narrow micropores and might present the same restrictions in the accessibility of ibuprofen, although in the case of LSN there is also an important contribution due to electrostatic repulsive interactions given the acidic carbon surface. In contrast, the largest ibuprofen uptake was attained in the carbons with the largest micropores: Q, P and CPAC.

It is interesting to note that Langmuir constant $b$ is higher for the carbons $\mathrm{P}$ and $\mathrm{CAC}$, which present rather low adsorption capacities, suggesting higher adsorption affinity of ibuprofen in both adsorbents. This can be attributed to the porous features of both carbons; more precisely, to their large volumes of narrow micropores (Table 1). On the other hand, the ibuprofen affinity seems to be lower for oxidized LSN than for LS carbon, as suggested by the shape of the isotherm. These observations point out also the role of the surface chemistry properties of the adsorbents on the uptake of ibuprofen. 


\section{Conclusions}

The potentialities of low-cost high-value activated carbons obtained cork powder and plastic residues for the removal of a widespread used drug (ibuprofen) were investigated. Due to a unique combination of basic nature of the surface groups along with micropores of adequate size, the waste-derived carbons outperformed the adsorption capacity of commercial adsorbents. The results from the effect of solution $\mathrm{pH}$ indicate that the $\mathrm{pH}_{\mathrm{PZC}}$ value seems to be an excellent marker for ibuprofen removal on activated carbons from aqueous solution. The waste-based activated carbons - CPAC and P - present the higher ibuprofen uptakes over a large $\mathrm{pH}$ range. 


\section{Acknowledgments}

This work was supported by FCT (Portugal) through the pluriannual programme of CQB. ASM thanks FCT for a PhD grant (SFRH/BD/17942/2004). COA thanks the Spanish MEC for a Ramon y Cajal research contract and the financial support of MICIN (project CTM2008-01956/TECNO). The authors thank NR Neng and FCM Portugal for technical assistance in HPLC measurements and Generis Farmacêutica SA (Portugal) for the ibuprofen supply. Bayer SA and Nanoquimia SL are kindly acknowledged for providing LS and Q carbons, respectively. 


\section{References}

Al-Ahmad, A., Daschner, R.D., Kummerer, K., 1999. Biodegradability of cefotiam, ciprofloxacin, meropenem, penicillin G, and sulfamethoxazole and inhibition of waste water bacteria. Arch. Environ. Contain. Toxicol. 37, 158-163.

Ania, C.O., Parra, J.B., Pis, J.J., 2004. Oxygen-induced decrease in the equilibrium adsorptive capacities of activated carbons. Ads. Sci. Technol. 22, 337-351.

Ania, C.O., Bandosz, T.J., 2005. Importance of structural and chemical heterogeneity of activated carbon surfaces for adsorption of dibenzothiophene. Langmuir 21, 7752-7759.

Association of plastic manufacturers in Europe, APME, www.plasticeurope.org .

Brunauer, B., Deming, L.S., Deming, W.E., Teller, E., 1940. On a theory of the van der Waals adsorption of gases. J. Am. Chem. Soc. 62, 1723-1732.

Cardoso, B., Mestre, A.S., Carvalho, A.P., Pires, J., 2008. Activated carbon derived from cork powder waste by $\mathrm{KOH}$ activation: preparation, characterization and VOCs adsorption. Ind. Eng. Chem. Res. 47, 5841-5846.

Carrott, P.J.M., Ribeiro-Carrott, M.M.L., Lima, R.P., 1999. Preparation of activated carbon "membranes" by physical and chemical activation of cork. Carbon 37, 515-517.

Carvalho, A.P., Gomes, M., Mestre, A.S., Pires, J., Carvalho, M. B., 2004. Activated carbons from cork waste by chemical activation with $\mathrm{K}_{2} \mathrm{CO}_{3}$ : Application to adsorption of natural gas components. Carbon 42 , 672-674.

Carvalho, A.P., Mestre, A.S., Pires, J., Pinto, M.L., Rosa, M.E., 2006. Granular activated carbons from powdered samples using clays as binders for the adsorption of organic vapors. Microp. Mesop. Mater. 93, 226-231.

Daughton, C.G., Ternes T.A., 1999. Pharmaceuticals and personal care products in the environment: Agents of subtle change? Environ. Health Perspect. 107, 907-938. 
Donnet, J.B., 1982. Structure and reactivity of carbons: from carbon black to carbon composites. Carbon 20, $267-282$.

Dubinin, M.M., Stoeckli, H.F., 1980. Homogeneous and heterogeneous micropore structures in carbonaceous adsorbents. J. Colloid Interface Sci. 75, 34-42.

Franz, M., Arafat, H.A., Pinto, N.G., 2000. Effect of chemical surface heterogeneity on the adsorption mechanism of dissolved aromatics on activated carbon. Carbon 38, 1807-1819.

Freundlich, H., 1926. Colloid and Capillary Chemistry, Methuen \& Co, London.

Gil, L., 1997. Cork powder waste: an overview. Biomass and Bioenerg. 13, 59-61.

Giles, C., Mc Ewan, T., Nakhwa, S., Smith, D.J., 1960. Studies in adsorption. Part XI. A system of classification of solutions adsorption isotherms, and its use in diagnosis of adsorption mechanisms and in measurement of specific surface areas of solids. J. Chem. Soc., 3973-3993.

Gomez, M.J., Martinez-Bueno, M.J., Lacorte, S., Fernandez-Alba, A.R., Aguera, A., 2007. Pilot survey monitoring pharmaceuticals and related compounds in a sewage treatment plant located on the Mediterranean coast. Chemosphere 66, 993-1002.

Hernando, M.D., Mezcua, M., Fernandez-Alba, A.R., Barceló, D., 2006. Environmental risk assessment of pharmaceutical residues in wastewater effluents, surface waters and sediments. Talanta 69, 334-342.

Ho, Y.S., 2004. Selection of optimum sorption isotherm. Carbon 42, 2115-2116.

Ho, Y.S., 2006. Review of second-order models for adsorption systems. J. Hazard. Mater. B136, 681-689.

Jones, O.A., Lester, J.N., Voulvoulis, N., 2005. Pharmaceuticals: a threat to drinking water? Trends Biotechnol. 23, 163-167.

Karagöz, S., Tay, T., Ucar, S., Erdem, M., 2008. Activated carbons from waste biomass by sulfuric acid activation and their use on methylene blue adsorption. Bioresour. Technol. 99, 6214-6222. 
Kolpin, D.W., Furlong, E.T., Meyer, M., Thurman, E.M., Zaugg, S.D., Barber, L.B., Buxton, H.A.T., 2002. Pharmaceuticals, hormones, and other organic wastewater contaminants in U.S. streams, 1999-2000: A national reconnaissance. Environ. Sci. Technol. 36, 1202-1211.

Langmuir, I., 1918. The adsorption of gases on plane surfaces of glass, mica and platinum. J. Am. Chem. Soc. $40,1361-1403$.

Lindqcist, N., Tuhkanen, T., Kronberg, L., 2005. Occurrence of acidic pharmaceuticals in raw and treated sewages and in receiving waters. Water Research 39, 2219-2228.

Mestre, A.S., Pires, J., Nogueira, J.M.F., Carvalho, A.P., 2007. Activated carbons for the adsorption of ibuprofen. Carbon 45, 1979-1988.

Michailof, C., Stavropoulos, G.G., Panayiotou, C., 2008. Enhanced adsorption of phenolic compounds, commonly encountered in olive mill wastewaters, on olive husk derived activated carbons. Bioresour. Technol. 99, 6400-6408.

Montes-Moran, M.A., Menendez, J.A., Fuente, E., Suarez, D., 1998. Contribution of the basal planes to carbon basicity: An ab-initio study of the $\mathrm{H}_{3} \mathrm{O}^{+}-\pi$ interaction in cluster models. J. Phys. Chem. B 102, 55955601.

Noh, J.S., Schwarz, J.A., 1989. Estimation of the point of zero charge of simple oxides by mass titration. J. Colloid Interface Sci. 130, 157-164.

Parra, J.B., Ania, C.O., Arenillas, A., Rubiera, F., Palacios, J.M., Pis, J.J., 2004. Textural development and hydrogen adsorption of carbon materials from PET waste. J. Alloys Compd. 379, 280-289.

Parra, J.B., Ania, C.O., Arenillas, A., Rubiera, F., Pis J.J., Palacios J.M., 2006. Structural changes in polyethylene terephthalate (PET) waste materials caused by pyrolysis and $\mathrm{CO}_{2}$ activation. Adsorp. Sci. Technol. 24, 439-450. 
POSEIDON, June 2004. Assessment of technologies for the removal of pharmaceuticals and personal care products in sewage and drinking water facilities to improve the indirect potable water reuse, Final Report. (http://poseidon.bafg.de/servlet/is/2888).

Roskill Report, 1998. The economics of activated carbon, Ed. Roskill Information Services Ltd., Claphham Road, London.

Silva, S.P., Sabino, M.A., Fernandes, E.M., Correlo, V.M., Boesel, L.F., Reis, R.L., 2005. Cork: properties, capabilities and applications. Int. Mater. Rev. 50, 345-357.

Sousa, A.F., Pinto, P.C.R.O., Silvestre, A.J.D., Neto, C.P., 2006. Triterpenic and other lipophilic components from industrial cork byproducts. J. Agric. Food Chem. 54, 6888-6893.

Stoeckli, H.F., Ballerini, L., 1991. Evolution of microporosity during activation of carbon. Fuel 70, 557-559.

Wang, S.-Y., Tsai, M.-H., Lo, S.-F., Tsai, M.-J., 2008. Effects of manufacturing conditions on the adsorption capacity of heavy metal ions by Makino bamboo charcoal. Bioresour. Technol. 99, 7027-7033. 
Figure 1

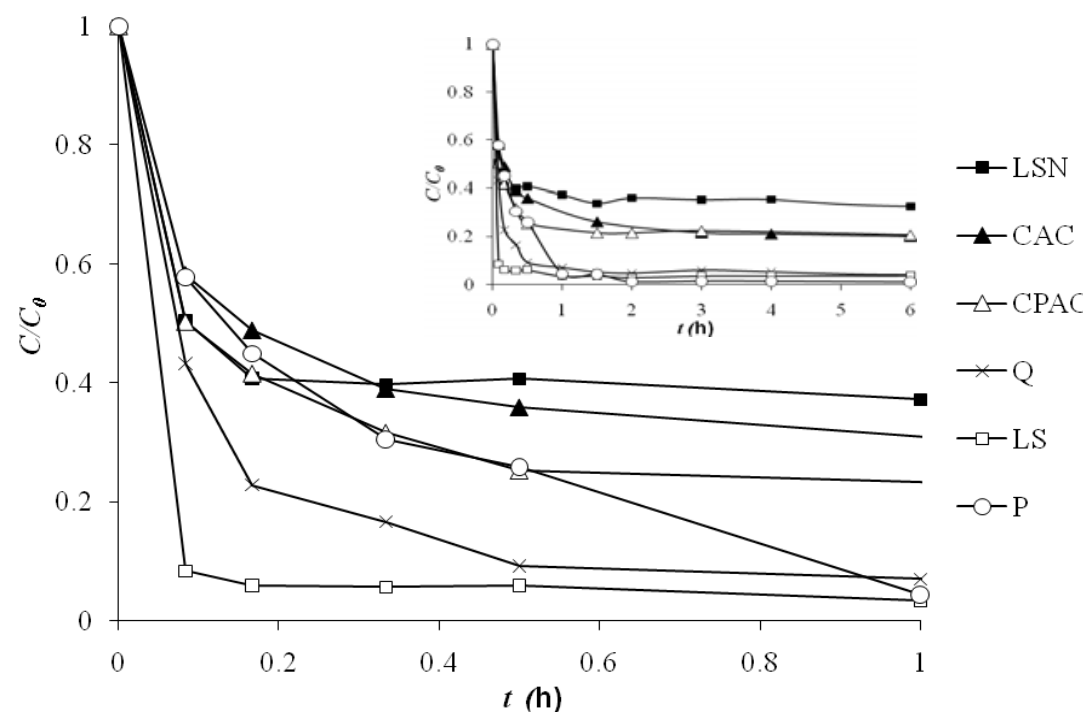


Figure 2

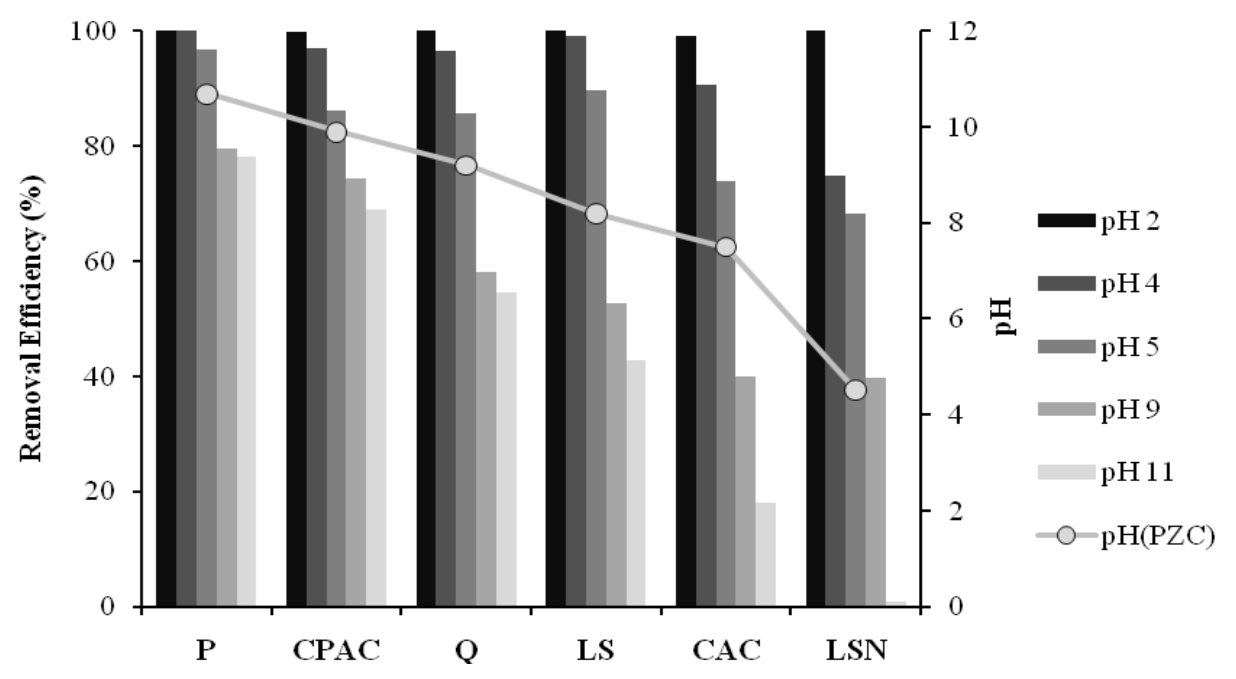


Figure 3

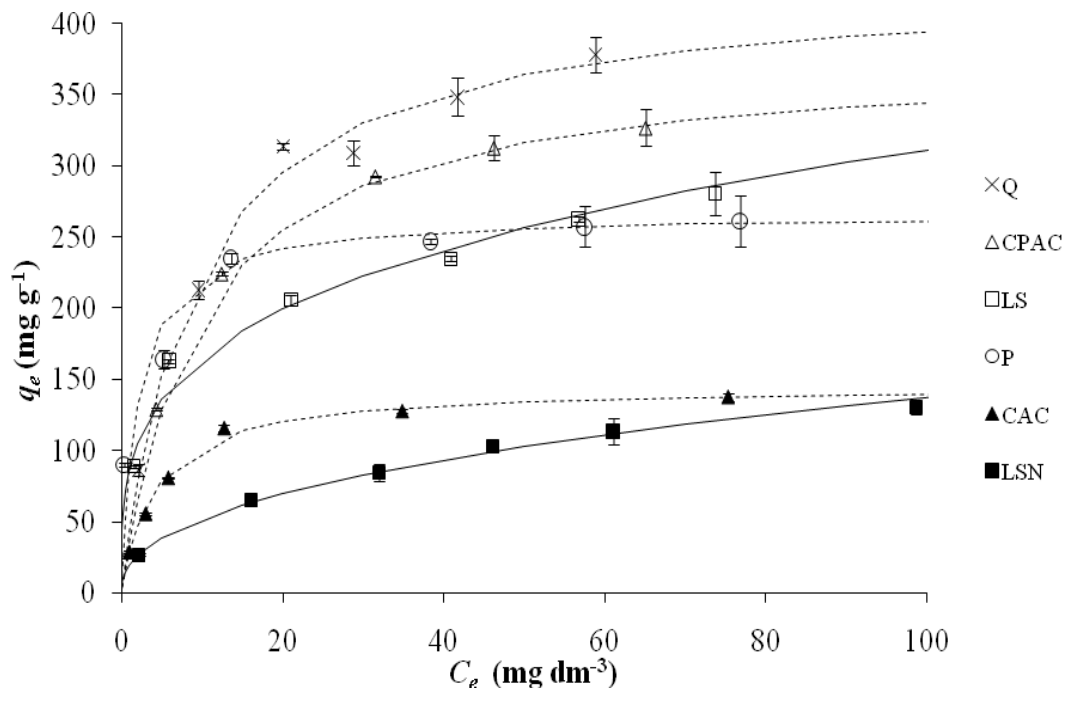


Figure 4

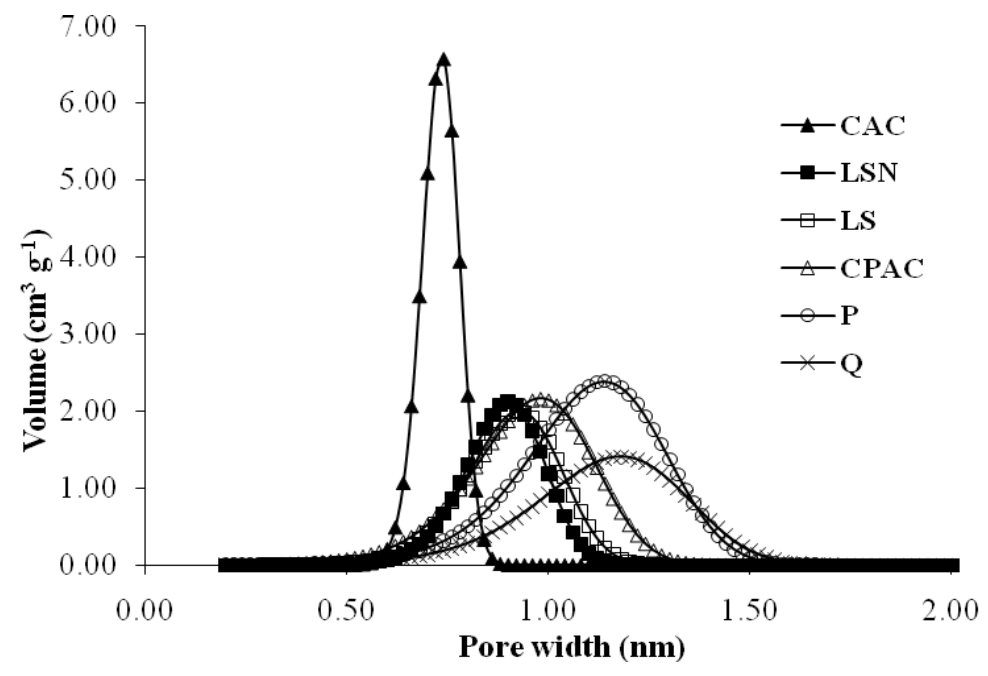


Table 1. Nanotextural and chemical characteristics of the waste-derived carbons and selected commercial adsorbents

\begin{tabular}{|c|c|c|c|c|c|c|c|c|c|}
\hline & \multicolumn{6}{|c|}{ nanotextural analysis } & \multicolumn{3}{|c|}{ chemical analysis } \\
\hline & $\begin{array}{l}S_{\mathrm{BET}} \\
\left(\mathrm{m}^{2} \mathrm{~g}^{-1}\right)\end{array}$ & $\begin{array}{l}V_{\text {TOTAL }}{ }^{\mathrm{a}} \\
\left(\mathrm{cm}^{3} \mathrm{~g}^{-1}\right)\end{array}$ & $\begin{array}{l}V_{\text {micro }} \\
\left(\mathrm{cm}^{3} \mathrm{~g}^{-1}\right)\end{array}$ & $\begin{array}{l}V_{\text {meso }}{ }^{-1} \\
\left(\mathrm{~cm}^{3} \mathrm{~g}^{-1}\right)\end{array}$ & $L^{\mathrm{c}}(\mathrm{nm})$ & $\begin{array}{l}W_{0 \mathrm{CO} 2}{ }^{\mathrm{d}} \\
\left(\mathrm{cm}^{3} \mathrm{~g}^{-1}\right)\end{array}$ & $\begin{array}{l}\text { Ash } \\
\text { (wt. \%) }\end{array}$ & $\begin{array}{l}\mathrm{O} \\
\text { (wt. \%) }\end{array}$ & $\mathrm{pH}_{\mathrm{PZC}}$ \\
\hline CAC & 891 & 0.420 & 0.308 & 0.007 & 0.74 & 0.381 & 4.1 & 9.8 & 7.5 \\
\hline CPAC & 1060 & 0.570 & 0.348 & 0.148 & 1.12 & 0.271 & 12.8 & 9.0 & 9.9 \\
\hline $\mathrm{P}$ & 1426 & 0.584 & 0.473 & 0.007 & 1.10 & 0.320 & $<1$ & $<1$ & 10.7 \\
\hline Q & 1156 & 0.646 & 0.330 & 0.143 & 1.49 & 0.182 & 11.4 & 2.0 & 9.2 \\
\hline LS & 899 & 0.626 & 0.251 & 0.183 & 1.05 & 0.255 & 1.4 & 3.3 & 8.2 \\
\hline LSN & 879 & 0.553 & 0.247 & 0.158 & 1.14 & 0.241 & $<1$ & 13.4 & 4.5 \\
\hline
\end{tabular}

${ }^{\mathrm{a}}$ evaluated at relative pressure $=0.95$ in the $\mathrm{N}_{2}$ adsorption isotherms at $-196^{\circ} \mathrm{C}$.

${ }^{\mathrm{b}}$ evaluated from the DFT method applied to the $\mathrm{N}_{2}$ adsorption isotherms at $-196^{\circ} \mathrm{C}$.

${ }^{\mathrm{c}}$ evaluated from the Stoeckli-Ballerini equation (Stoeckli and Ballerini, 1991) applied to the $\mathrm{N}_{2}$ adsorption isotherms at $-196^{\circ} \mathrm{C}$.

${ }^{\mathrm{d}}$ evaluated from the DR method applied to the $\mathrm{CO}_{2}$ adsorption isotherms at $0{ }^{\circ} \mathrm{C}$. 
Table 2. Pseudo-second order ibuprofen adsorption parameters for the studied carbon samples at $30{ }^{\circ} \mathrm{C}: k_{2}$ is the pseudo-second order rate constant; $h$ is the initial adsorption rate; $t_{1 / 2}$ is the half-life time; $q_{\mathrm{e}, \text { calc }}$ and $C_{\mathrm{e}, \text { calc }}$, are respectively, the ibuprofen uptake and that remaining in solution at equilibrium both calculated by the pseudo-second order kinetic model, and re is the removal efficiency.

\begin{tabular}{llllllll}
\hline Sample & $\begin{array}{l}k_{2} \\
\left(\mathrm{~g} \mathrm{mg}^{-1} \mathrm{~h}^{-1}\right)\end{array}$ & $R^{2}$ & $\begin{array}{l}h \\
\left(\mathrm{mg} \mathrm{g}^{-1} \mathrm{~h}^{-1}\right)\end{array}$ & $\begin{array}{l}t_{1 / 2} \\
(\mathrm{~h})\end{array}$ & $\begin{array}{l}q_{\mathrm{e}, \mathrm{calc}} \\
\left(\mathrm{mg} \mathrm{g}^{-1}\right)\end{array}$ & $\begin{array}{l}C_{\mathrm{e}, \mathrm{calc}} \\
\left(\mathrm{mg} \mathrm{dm}^{-3}\right)\end{array}$ & $\begin{array}{l}\text { re * } \\
(\%)\end{array}$ \\
\hline CAC & 0.07 & 0.999 & 834 & 0.135 & 112.4 & 15.1 & 83.2 \\
CPAC & 0.22 & 0.999 & 2500 & 0.042 & 106.4 & 19.1 & 78.8 \\
P & 0.06 & 0.999 & 1250 & 0.111 & 138.9 & 0.5 & 99.5 \\
Q & 0.14 & 0.999 & 2500 & 0.053 & 131.6 & 2.3 & 97.4 \\
LS & 0.58 & 0.999 & 9993 & 0.013 & 131.6 & 2.3 & 97.4 \\
LSN & 0.25 & 0.999 & 2002 & 0.045 & 89.3 & 30.5 & 66.1 \\
\hline
\end{tabular}

$*_{\mathrm{re}}=\frac{\left(C_{0}-C_{e, \text { calc }}\right)}{C_{0}} \times 100$ 
Table 3. Fitting parameters to the Langmuir and Freundlich models and chi-square test analysis, $\chi^{2}$.

\begin{tabular}{|c|c|c|c|c|c|c|}
\hline & \multicolumn{3}{|c|}{ Langmuir Equation } & \multicolumn{3}{|c|}{ Freundlich Equation } \\
\hline & $\begin{array}{l}q_{\mathrm{m}} \\
\left(\mathrm{mg} \mathrm{g}^{-1}\right)\end{array}$ & $\begin{array}{l}b \\
\left(\mathrm{dm}^{3} \mathrm{mg}^{-1}\right)\end{array}$ & $\chi^{2 *}$ & $1 / n$ & $\begin{array}{l}K_{\mathrm{F}} \\
\left(\mathrm{mg}^{1-1 / \mathrm{n}}\left(\mathrm{dm}^{3}\right)^{1 / \mathrm{n}} \mathrm{g}^{-1}\right)\end{array}$ & $\chi^{2 *}$ \\
\hline CAC & 145.2 & 0.238 & 1.02 & 0.356 & 36.6 & 17.27 \\
\hline CPAC & 378.1 & 0.104 & 3.09 & 0.560 & 40.5 & 63.03 \\
\hline $\mathrm{P}$ & 266.6 & 0.486 & 4.19 & 0.200 & 118.6 & 7.81 \\
\hline Q & 430.4 & 0.109 & 2.77 & 0.446 & 69.3 & 19.8 \\
\hline LS & 291.9 & 0.166 & 6.37 & 0.278 & 86.7 & 3.65 \\
\hline LSN & 149.1 & 0.055 & 1.34 & 0.423 & 19.6 & 0.54 \\
\hline
\end{tabular}

$* \chi^{2}=\sum \frac{\left(q_{e}-q_{e, m}\right)^{2}}{q_{e, m}}$ where $q_{\mathrm{e}}$ is the experimental equilibrium uptake and $q_{\mathrm{e}, \mathrm{m}}$ is the equilibrium uptake calculated from the model (Ho, 2004). 